\title{
Laparoscopic adjustable gastric banding's multiple complications: when complications arise even after 30 years, a case report.
}

\author{
Denise Gambardella ${ }^{1}$, Antonella Capomollaํ, Rosalinda Filippo ${ }^{1}$, Angelo Aldo Schicchi ${ }^{2}$, Luigino Borrello ${ }^{3}$, \\ Manfredo Tedesco
}

1Department of General Surgery, University of Catanzaro, Catanzaro, Italy.
2Operative Unit of Endoscopy, "Giovanni Paolo II” Hospital, Lamezia Terme, Italy.
${ }^{3}$ Operative Unit of General Surgery, "Giovanni Paolo II” Hospital, Lamezia Terme, Italy, (Director Manfredo Tedesco).

\section{To Cite}

Gambardella D, Capomolla A, Filippo R, Schicchi A A, Borrello L, Tedesco M. Laparoscopic adjustable gastric banding's multiple complications: when complications arise even after 30 years, a case report. J Gastric Surg 2020; 2(4).

\section{Publication history}

Received: September 25, 2020

Accepted: October 01, 2020

Article in press: October 06, 2020

Published online: October 07, 2020

\section{*Correspondence to}

Denise Gambardella, MD

Department of General Surgery, University of Catanzaro, Catanzaro, Italy. gambardelladenise@gmail.com

\section{ABSTRACT}

Laparoscopic adjustable gastric banding (LAGB) is a popular bariatric surgical procedure. The introduction of laparoscopy has increased the use of this procedure, making it the most commonly performed bariatric surgery. Patients undergoing LAGB have achieved satisfactory results in terms of weight loss, a reduction in co-morbidities, and improved quality of life. Nonetheless, complications with LAGB are well documented and include migration, erosion, prolapse, infection, pouch dilation, gastric perforation, and most commonly, lack of weight loss following the failure of the procedure. This case report presents a patient with slippage and pouch dilation, erosion of the stomach, and port site problems, including infection, occurring 28 years after LAGB.

Keywords:

Laparoscopic adjustable gastric banding, LAGB, long-term complication, reoperation. 


\section{Background}

Currently, obese patients are being offered an increasing number of treatment options, including bariatric surgery, a popular and viable therapeutic choice. Among the most frequently performed bariatric procedures, laparoscopic adjustable gastric banding (LAGB) has the lowest morbidity and mortality rates, despite being burdened with complications such as band slippage and erosion that often require revisionary surgery.[1] In this report, we describe the complex case of a 73-year-old female patient with a body mass index (BMI) of $41.6 \mathrm{~kg} / \mathrm{m} 2$ who underwent LAGB in September 1992 and came to our attention 28 years later, presenting with fever, epigastric pain, and multiple LAGB-related complications, which necessitated laparoscopic removal.

\section{Case Report}

A 73-year-old Caucasian female presented to the emergency department feeling generally unwell and reporting fever and abdominal pain over the past 14 days. She had a history of pain, nausea, and vomiting. Her medical history was significant for severe obesity, with a BMI of $41.6 \mathrm{~kg} / \mathrm{m} 2$, diabetes, hypertension, and LAGB 28 years prior. Upon examination, the patient had abdominal pain, especially in the epigastric region, and pain and redness from the LAGB port. Her laboratory results showed leukocytosis $(16,000 / \mathrm{mm} 3)$ and a $C$ reactive protein level of $157 \mathrm{mg} / \mathrm{L}$. A direct abdominal $\mathrm{X}$-ray and routine gastrografin upper gastrointestinal series showed a slippage of the band. To rule out suspicion of erosion of the gastric wall, we carried out an abdominal CT scan, which came back positive for leakage, free air, and inflammation around the port. A laparoscopy was performed, and multiple adhesions, with evidence of inflammation, were seen in the upper abdomen, around the band, and between the stomach and the liver.

Initially, there was no visualization of the band; however, with blunt and gentle maneuvers, using the harmonic ace, we isolated the band and cut it off with scissors (Figure 1).

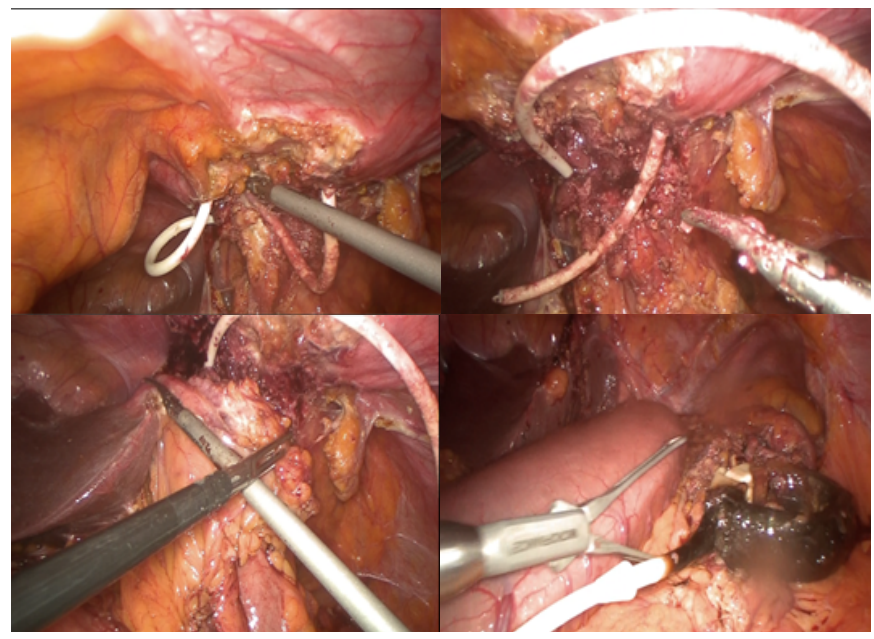

Figure 1: surgical steps for bandage removal: lysis of the adhesions between the stomach, liver, and abdominal wall.

During the maneuvers to remove the bandage, the presence of stomach erosion on the anterior wall was highlighted, and the breach was approached with forceps and sutured with a $45 \mathrm{~mm}$ endostapler using a load for thick tissues (Figure 2).

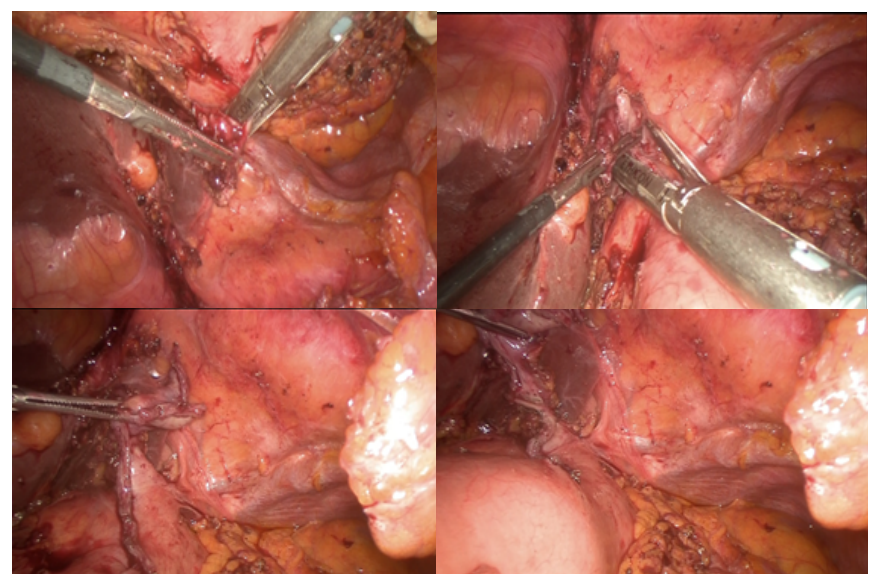

Figure 2: dissection around the gastric lesion and removal of the eroded tissue using a mechanical stapler.

A peri-gastric drain was placed and a nasogastric tube was left in place postoperatively. The operation lasted 50 minutes. There was no blood loss and no intra- or postoperative complications.

The nasogastric tube and drain were removed on postoperative day 2 , and on postoperative day 3 , the patient resumed oral intake, beginning with liquids. The patient was discharged from the hospital on postoperative day 5. At the postoperative control, no complications were seen after 1 month and 3 months.

\section{Discussion}

LAGB is a restrictive operation frequently performed on obese patients, together with laparoscopic sleeve gastrectomy.[1,2] For prolonged weight loss, bariatric surgery is currently the only effective treatment for obesity beyond lifestyle change and various drug treatments.[3] The first adjustable gastric band was implanted by Kuzmak in the 1980s using laparotomy. With the advent of laparoscopic surgery, providing a minimally invasive approach, LABG became an effective option to treat obesity.[4,5] The introduction of laparoscopy has increased the international popularity of LAGB, making it the most common bariatric surgery in the world.[6] Several studies have indicated how quickly patients lose weight over the years.[7-11] Most international studies have shown that weight loss occurs within two years of the procedure, with a peak in weight loss at $3-4$ years. $[7,12,13]$.

Patients undergoing LAGB have achieved excellent results in terms of quality of life, weight loss, and reduction in comorbid conditions.[14] Nonetheless, complications of LAGB are well documented in the literature.[10,12,15-17] Complications following gastric banding can be divided into band-related and portrelated issues. If present, these complications can lead to the general failure of the procedure and make the patient susceptible to major infectious complications. Considering the long-term complication rate of $40 \%$ $[18,19]$, in case of doubt regarding the onset of these complications, diagnostic investigations must be carried out. In the case examined, the patient had a 
double problem: a band-related complication that had also caused a gastric lesion, and a port-related one for the pocket infection. The most common LAGB-related complications include pouch dilation (or enlargement) and band slippage, reported in 1-21\% of LAGB patients. [20] In comparison, gastric prolapse, gastric obstruction, esophageal dilation, band erosion, gastric necrosis, and port problems represent less common complications. $[14,20]$

Other complications described include cholelithiasis/ cholecystitis, ventral hernia, dehydration, hemorrhage, pancreatitis, leak, and injury during the operation (liver hematoma/spleen injury).[10] Gastric necrosis is an extremely rare but potentially fatal complication of LAGB, typically developing because of prolapse, pouch dilation, or obstruction.[18] Overall, a complication incidence of $1.2 \%$ and a late reoperation rate of $12.5 \%$ have been reported.[11]

\section{Conclusion}

We presented a difficult case involving multiple complications related to LAGB, which necessitated laparoscopic removal. The complications were bandrelated and port-related: band slippage, gastric lesion, pocket infection, and trocar site hernia as well as the failure of the procedure in terms of a lack of weight loss. She was investigated for possible sources of sepsis. In conclusion, we advocate the need for careful follow-up for all patients with a history of LAGB who present with abdominal complaints, even though the band is correctly positioned. Whenever LAGB-related complications are suspected, patients should be monitored closely. If the symptoms persist or the pouch remains dilated, a prompt diagnostic operation should be performed to avoid more severe complications, such as gastric necrosis. To avoid complications related to LAGB, at the first abdominal symptoms, we suggest direct abdominal X-ray and a routine gastrografin upper gastrointestinal series for earlier identification and intervention in order to minimize morbidity and mortality in patients who develop a leak.[21] In case of suspicion of erosion of the gastric wall or suffering, perform an abdominal CT scan, searching for alteration of wall enhancement and intramural air density along the gastric wall or gastric pneumatosis. A plain radiograph can reveal if the band is oriented correctly or a gastric distention is evident. The success of the intervention and the avoidance of potentially serious complications also depend on the follow-up that this type of patient must undergo, which must be pursued even after many years, as in this case, the patient immediately stopped undergoing the band monitoring, leading to potentially fatal complications almost 30 years later.

\section{Acknowledgements \\ None}

\section{Contributors}

DG, AC, RF, AAS, LB, MT conceptualized and designed the study, acquired, and analyzed data, interpreted the study results, drafted the manuscript, and critically revised the final version of the manuscript.

\section{Funding}

No funding was received for this study.

\section{Competing interests}

No benefits in any form have been received or will be received from a commercial party related directly or indirectly to the subject of this article.

\section{Availability of data and materials}

Further information is available from the corresponding author on reasonable request.

\section{Ethics approval \\ Not applicable.}

\section{Provenance and peer review}

Not commissioned; externally peer reviewed.

\section{Open access}

This is an Open Access article distributed in accordance with the Creative Commons Attribution NonCommercial (CC BY-NC 4.0) license, which permits others to distribute, remix, adapt, build upon this work noncommercially, and license their derivative works on different terms, provided

the original work is properly cited and the use is non-commercial. See: http://creativecommons.org/ licenses/by-nc/4.0/

\section{References}

[1] Singhal R, Bryant C, Kitchen M, Khan KS, Deeks J, Guo B, et al. Band slippage and erosion after laparoscopic gastric banding: a metaanalysis. Surg Endosc. 2010;24:2980-6.

[2] Ahn HS, Lee HJ, Kang SH, Kim GJ, Kim SS, Kim YJ. 2013 Nationwide bariatric and metabolic surgery report in Korea. J Metab Bariatr Surg. 2014;3:38-43

[3] Sjostrom L, Narbro K, Sjostrom CD, Karason K, Larsson B, Wedel $\mathrm{H}$, et al. Effects of bariatric surgery on mortality in Swedish obese subjects. N Engl J Med. 2007;357:741-52.

[4] Kuzmak LI. A Review of Seven Years' Experience with Silicone Gastric Banding. Obes Surg. 1991;1:403-8.

[5] Steffen R. The history and role of gastric banding. Surg Obes Relat Dis. 2008;4:S7-13.

[6] Buchwald H, Williams SE. Bariatric surgery worldwide 2003. Obes Surg. 2004;14:1157-64.

[7] Dargent J. Surgical treatment of morbid obesity by adjustable gastric band: the case for a conservative strategy in the case of failure a 9-year series. Obes Surg. 2004;14:986-90.

[8] Vertruyen M. Experience with Lap-band System up to 7 years. Obes Surg. 2002;12:569-72.

[9] Weiner R, Blanco-Engert R, Weiner S, Matkowitz R, Schaefer L, Pomhoff I. Outcome after laparoscopic adjustable gastric banding - 8 years experience. Obes Surg. 2003;13:427-34.

[10] Weichman K, Ren C, Kurian M, Heekoung AY, Casciano R, Stern $\mathrm{L}$, et al. The effectiveness of adjustable gastric banding: a retrospective 6-year U.S. follow-up study. Surg Endosc. 2011;25:397-403.

[11] O'Brien PE, Dixon JB, Brown W, Schachter LM, Chapman L, Burn AJ, et al. The laparoscopic adjustable gastric band (Lap-Band): a prospective study of medium-term effects on weight, health and quality of life. Obes Surg. 2002;12:652-60.

[12] O'Brien PE, McPhail T, Chaston TB, Dixon JB. Systematic review of medium-term weight loss after bariatric operations. Obes Surg. 2006;16:1032-40.

[13] Ponce J, Paynter S, Fromm R. Laparoscopic adjustable gastric banding: 1,014 consecutive cases. J Am Coll Surg. 2005;201:529-35.

[14] O'Brien PE, MacDonald L, Anderson M, Brennan L, Brown WA. Long-term outcomes after bariatric surgery: fifteen-year follow-up of adjustable gastric banding and a systematic review of the bariatric surgical literature. Ann Surg. 2013;257:87-94.

[15] Belachew M, Belva PH, Desaive C. Long-term results of laparoscopic adjustable gastric banding for the treatment of morbid obesity. Obes Surg. 2002;12:564-8.

[16] Allen JW. Laparoscopic gastric band complications. Med Clin 
North Am. 2007;91:485-97, xii.

[17] O'Brien PE, Dixon JB. Lap-band: outcomes and results. J Laparoendosc Adv Surg Tech A. 2003;13:265-70.

[18] Kim EY, Kim YJ. Life-threatening late complication after laparoscopic adjustable gastric banding: two cases of gastric necrosis. Surg Obes Relat Dis. 2016;12:e5-9.

[19] Moser F, Gorodner MV, Galvani CA, Baptista M, Chretien C, Horgan S. Pouch enlargement and band slippage: two different entities. Surg Endosc. 2006;20:1021-9.

[20] Shen X, Zhang X, Bi J, Yin K. Long-term complications requiring reoperations after laparoscopic adjustable gastric banding: a systematic review. Surg Obes Relat Dis. 2015;11:956-64.

[21] Vitello DJ, Vitello JM, Beach-Bachmann J, Bentrem D. Value

of Routine Gastrografin Upper Gastrointestinal Study After Sleeve Gastrectomy. JAMA Surg. 2019;154:181-2. 